\title{
Concomitant bilateral popliteal arterial aneurysm and abdominal aortic aneurysm in a case with severe occlusive disease of lower extremity
}

\author{
U Yetkin ${ }^{*}$, I Peker, $\mathrm{H}$ Iner, I Yurekli, A Gurbuz \\ From 23rd World Congress of the World Society of Cardio-Thoracic Surgeons \\ Split, Croatia. 12-15 September 2013
}

\section{Background}

Aneurysmal dilation of popliteal artery's diagnosis is quite difficult due to its insidious and asymptomatic course although it consists of $2 / 3$ of all peripheral arterial aneurysms.

\section{Methods}

Our case was a 53-year-old male. He was presented to our surgical council after detailed investigations carried out at another institution. His past medical history was significant for left infragenual femoropopliteal bypass using PTFE graft 2 years ago. He was complaining from claudication of his left lower extremity at a walking distance of $100 \mathrm{~m}$.

\section{Results}

Color Doppler ultrasound revealed bilateral popliteal arterial aneurysm of 2-2.5 $\mathrm{cm}$. Computed tomographic angiography showed a fusiform aneurysmal dilation of the abdominal aorta with a largest diameter of $38 \mathrm{~mm}$. Left superficial femoral artery was totally occluded and the graft was patent. There was a high-grade stenosis at the site of proximal anastomosis. Both popliteal arteries showed aneurysmal dilation of 35 and $25 \mathrm{~mm}$, right and left sides, respectively. Right peroneal artery was patent but the remaining two branches were perfused via collaterals. All of the 3 infragenual branches were patent on left with occlusion of the anterior tibial artery distally. Pedal arteries were patent. Coronary angiogram discovered some non-significant stenotic lesions at left anterior descending and right coronary arteries. With these findings, we planned percutaneous balloon dilation

\footnotetext{
* Correspondence: ufuk_yetkin@yahoo.fr

Department of Cardiovascular Surgery, Izmir Katip Celebi University Ataturk Training and Research Hospital, Izmir, Turkey
}

or, if necessary, stenting of the proximal anastomosis site and endovascular stent grafting of both popliteal arteries. He preferred to remain in outpatient follow-up.

\section{Conclusions}

Popliteal arterial aneurysms may be seen bilaterally and coexistent abdominal aortic aneurysm may be detected in $50 \%$ of cases. The priority in the treatment of the aneurysm includes prevention of limb ischemia or limb loss. In addition to the open surgical approach, endovascular stent grafting gains popularity and becomes a widely performed application.

Published: 11 September 2013

\section{doi:10.1186/1749-8090-8-S1-P90}

Cite this article as: Yetkin et al:: Concomitant bilateral popliteal arterial aneurysm and abdominal aortic aneurysm in a case with severe occlusive disease of lower extremity. Journal of Cardiothoracic Surgery 2013 8(Suppl 1):P90.

Submit your next manuscript to BioMed Central and take full advantage of:

- Convenient online submission

- Thorough peer review

- No space constraints or color figure charges

- Immediate publication on acceptance

- Inclusion in PubMed, CAS, Scopus and Google Scholar

- Research which is freely available for redistribution 